\title{
A Description of the CSU-CHILL National Radar Facility
}

\author{
DAVID BRUNKOW \\ Department of Atmospheric Science, Colorado State University, Fort Collins, Colorado \\ V. N. BRINGI \\ Department of Electrical Engineering, Colorado State University, Fort Collins, Colorado \\ Patrick C. Kennedy and Steven A. Rutledge \\ Department of Atmospheric Science, Colorado State University, Fort Collins, Colorado \\ V. CHANDRASEKAR \\ Department of Electrical Engineering, Colorado State University, Fort Collins, Colorado \\ E. A. Mueller And Robert K. Bowie \\ Department of Atmospheric Science, Colorado State University, Fort Collins, Colorado
}

(Manuscript received 19 May 1999, in final form 29 November 1999)

ABSTRACT

\begin{abstract}
The subject of this paper is the Colorado State University-University of Chicago-Illinois State Water Survey (CSU-CHILL) National Radar Facility's S-band polarimetric research radar. Key features of this system include polarization agility (provided by the dual-transmitter, dual-receiver design), a recently updated signal processor, and a low ( $-34 \mathrm{~dB}$, two way) integrated cross-polar ratio $\left(\mathrm{ICPR}_{2}\right)$ antenna system. After reviewing the technical description of the radar, the authors present a new differential reflectivity $\left(Z_{\mathrm{DR}}\right)$ calibration technique and data examples collected in different polarization modes.

Although the CSU-CHILL radar is transportable, it can also be operated in a dual-Doppler configuration with the CSU-Pawnee radar, an 11-cm Doppler radar system situated $48 \mathrm{~km}$ north of the CSU-CHILL Greeley field site. Used together, these radars provide three-dimensional kinematic and hydrometeor information in precipitating cloud systems.
\end{abstract}

\section{Introduction}

Meteorological radars have proven to be of great utility in remotely sensing the structure and evolution of clouds and precipitation. Within the last decade, significant advances have been made in the application of polarization diversity technology to meteorological radar (Bringi and Hendry 1990; Doviak and Zrnic 1993).

The foundation of microwave radar remote sensing is the acquisition of useful target information based upon the amplitude and phase characteristics of the signal received due to backscattering. Polarimetric radar systems typically transmit and receive signals with two

Corresponding author address: David Brunkow, Department of Atmospheric Science, Colorado State University, Fort Collins, CO 80523.

E-mail: dave@1ab.chill.colostate.edu orthogonal polarizations. By analyzing the polarization components of the return signal, information regarding the mean shape, orientation, and thermodynamic phase of the particles in the pulse volume can be obtained (McCormick and Hendry 1975; Jameson 1985; Jameson and Johnson 1990).

In concept, virtually all dual-polarization measurements involve the quantification of some change in the received signal characteristics based on the transmitted polarization state. Often the characteristics of these polarization-dependent signals make their precision measurement very difficult (i.e., small magnitudes, large variances, etc.). To minimize system-induced errors, dual-polarization radars must be carefully designed. In particular, the main radiation lobe of the antenna should illuminate each sample volume with radiation of high polarization purity (McCormick 1981). Receivers for both the copolar and cross-polar return signal components are necessary to measure the target's backscat- 
tering matrix (McCormick and Hendry 1975, 1979). These receivers must have high sensitivities and be very stable. Furthermore, the handling and presentation of the increased quantities of data generated by multiparameter radars require the use of high-capacity digital signal processing systems and interactively controlled color displays.

From its initial joint development by the University of Chicago and the Illinois State Water Survey (CHILL; Mueller and Silha 1978), the CHILL radar has been designed to be a transportable S-band radar system with dual-polarization capabilities. In 1990, operation of the radar was transferred to Colorado State University (CSU). Since that time, the polarimetric performance of this system has been considerably improved through continuing design evolution. These enhancements include the installation of a new reflector antenna in 1994 and the implementation of a second transmitter and receiver chain in 1995. Recently, new intermediate frequency (IF) digitizing receivers and high-speed signal processors have been added to the system for improved flexibility, stability, and precision (Wu 1998).

\section{CSU-CHILL radar system design}

\section{a. Transmitter and receiver considerations}

Historically, an electronically controlled, high-power ferrite switch was used in the CHILL system to alternately connect the antenna's horizontal $(\mathrm{H})$ and vertical (V) polarization ports to the single-channel transmitter and receiver (Mueller 1981). The isolation (between $\mathrm{H}$ and $\mathrm{V}$ signals) of ferrite switches of this type is affected by both temperature and transmitter pulse repetition frequency. When tuned for stable operation, the isolation between the $\mathrm{H}$ and $\mathrm{V}$ channels through such switches is generally no greater than $25 \mathrm{~dB}$ (Carter et al. 1986). This isolation value directly limits the system's sensitivity to cross-polarized return signals and therefore determines the lower limit to the measurement of the linear depolarization ratio (LDR).

This limitation was overcome in 1995 by adding a separate, identical FPS-18 transmitter to the system. The two transmitters individually drive the $\mathrm{H}$ and $\mathrm{V}$ polarization ports of the antenna through a dual-channel rotary waveguide joint, eliminating the need for the ferrite polarization switch. The dual-channel rotary joint maintains an interchannel isolation of greater than $50 \mathrm{~dB}$, thus providing a substantial improvement over the isolation attained by the high power ferrite switch. The LDR performance of the system is then determined by the cross-pole isolation characteristics of the antenna (discussed in section 3).

\section{b. Block diagram}

A simplified block diagram of the current CSUCHILL transmitter and receiver configuration is shown

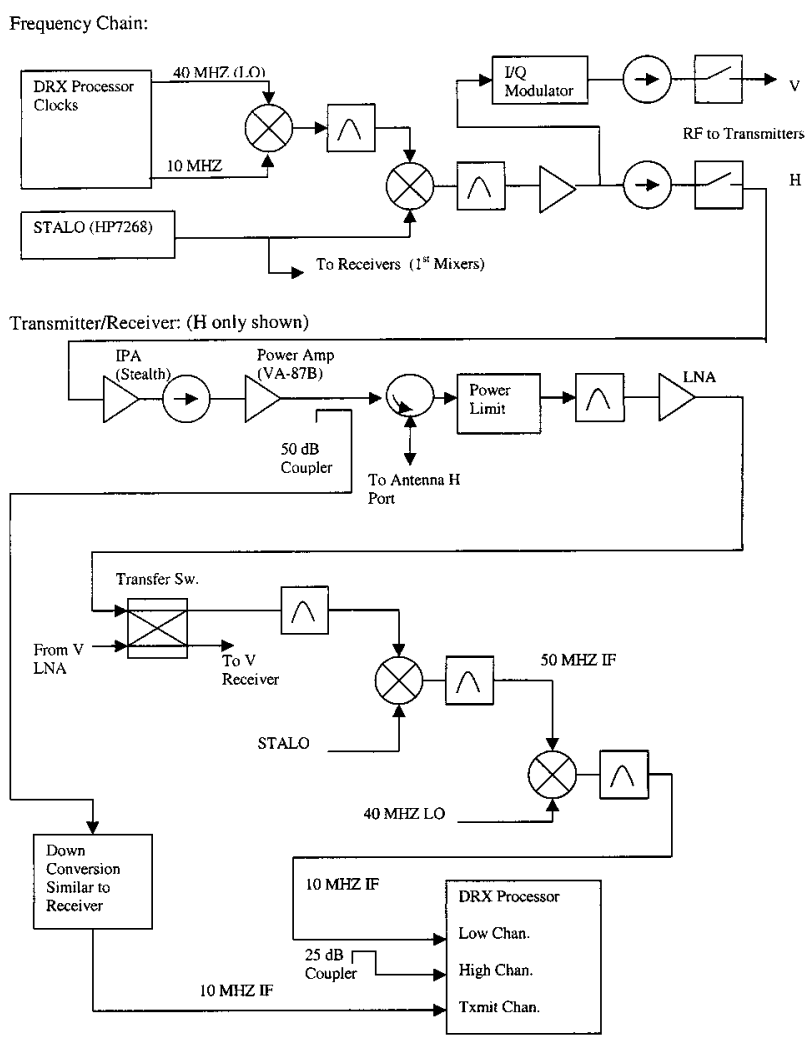

FIG. 1. Simplified CSU-CHILL radar block diagram.

in Fig. 1. The design of the frequency chain and receiver was modified considerably in 1999 to accommodate a new IF-digitizing signal processor (Lassen Aspen/ DRX). The transmitters share a common stable local oscillator (STALO). The STALO is mixed with a 50$\mathrm{MHz}$ source derived from the processor clock to produce the transmit frequency. The vertical channel transmit drive signal can be further adjusted by an I/Q vector modulator to permit adjustments of the relative phase and amplitude between the $\mathrm{H}$ and $\mathrm{V}$ transmitted pulses. Although alternate triggering mode is most commonly used, the transmitters may also be triggered simultaneously based on pulses generated in the signal processor state machine. When the transmitters are triggered simultaneously and the appropriate interchannel phase adjustment is applied, the radiated polarization can be set to slant $\pm 45^{\circ}$ linear or right-hand or lefthand circular polarization states. Separate digital power meters monitor the average RF output level developed by each transmitter. These digitized power readings are inserted into the recorded data stream at 2-s intervals so that accurate reflectivity and differential reflectivity calibrations can be maintained. Once the transmitters are fully stabilized ( $\sim 30 \mathrm{~min})$, the output power levels generally vary by less than $0.3 \mathrm{~dB}$ during the course of a normal data collection period $(\sim 10 \mathrm{~h})$.

Return signals are passed through a pair of separate matched receivers. The low noise amplifier (LNA) and 


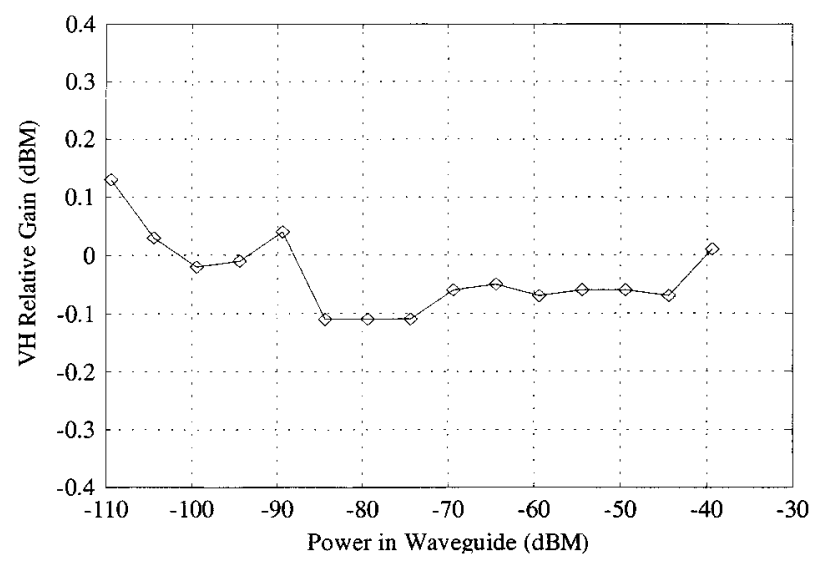

FIG. 2. Gain difference as a function of input power.

first mixers for both receivers are mounted on the same aluminum plate. The temperature of the plate is held at a constant value $\left(20^{\circ} \mathrm{C}\right)$ by a thermostatically controlled Peltier effect cooler. The minimization of temperature variations between the "front end" components of the two receiver channels reduces the tendency for differential drifts to develop in the calibration characteristics of the two receivers.

A solid state transfer switch located after each LNA permits the $\mathrm{H}$ and $\mathrm{V}$ received signals returning from the antenna to be connected to either receiver channel. Prior to 1999 , the transfer switch was used to route all the copolar signals to one receiver and all the cross-polar signals to the other receiver. In the alternating $\mathrm{VH}$ operational mode, this switch was toggled just before each pulse was transmitted. The reasoning was that using a single receiver to develop the copolar radar measurables, such as $Z_{\mathrm{H}}$, the differential reflectivity $\left(Z_{\mathrm{DR}}\right)$, the differential phase $\left(\phi_{\mathrm{DP}}\right)$, and the copolar correlation coefficient $\left(\rho_{\mathrm{HV}}\right)$ (Doviak and Zrnic 1993) would reduce errors due to calibration differences and drift in the two receivers. The stability and linearity of the current digital receivers are believed to be of sufficiently high quality that the transfer switch, while still in the circuit, is not currently in use. Figure 2 indicates the power difference as measured by the two receivers when both receivers were driven by a test signal that was split and fed into both waveguides simultaneously. The results indicate less than 0.1-dB difference in gain between the $\mathrm{H}$ and the $\mathrm{V}$ receivers over a wide dynamic range.

From the transfer switch, the received signals pass through image rejection filters and are down converted to a $50-\mathrm{MHz}$ IF by mixing with the STALO frequency. A second conversion to the $10-\mathrm{MHz}$ IF is performed by mixing with the $40-\mathrm{MHz}$ reference clock from the processor. The IF signal is converted by 12-bit digitizers running at a $40-\mathrm{MHz}$ rate. Programmable FIR filter chips then apply quadrature detection followed by lowpass filtering to produce in-phase (I) and quadrature (Q) voltage numbers. Each processor performs these functions in a pair of receiver channels separated in sensi- tivity by $25 \mathrm{~dB}$. When all samples are complete for a given integration period, the set that offers the most sensitivity without excessive saturation will be selected for processing. To facilitate this channel selection process, each range gate has a counter to keep track of the number of saturated samples encountered during each integration cycle. The bank of counters is available to the digital signal processors (DSPs), where the actual decision on which receiver channel to use is made. New directional couplers have been added between the transmitters and the circulators, which provide a high quality sample of each transmitted pulse that is downconverted to $10 \mathrm{MHz}$, just as it is done in the receiver. The transmit sample is then fed to a third input channel on each processor, where the pulse is digitized at a $40-\mathrm{MHz}$ rate. The processor uses these samples to calculate the average amplitude and phase of each pulse and optionally uses these results to correct the received signals from that pulse for slight variations in phase and magnitude. Although the phase stability of the new system has not yet been measured, these corrections are expected to produce mean phase estimation accuracies of better than $0.1^{\circ}$. A series of Analog Devices SHARC DSP chips performs this correction, applies clutter filtering, and does covariance processing. A third-party SHARCbased processor board is used to calculate the meteorological moments. The data stream is passed to a workstation for archiving and further distribution. The SHARC digital signal processing chips offer considerable computational capability with a software development environment, which allows most of the programming to be done in the $\mathrm{C}$ language.

In the alternate $\mathrm{VH}$ triggering mode, both the copolar $H$ received from $H$ transmitted $(\mathrm{HH})$ and $V$ received from $\mathrm{V}$ transmitted (VV) as well as the cross-polar $\mathrm{V}$ received from $\mathrm{H}$ transmitted $(\mathrm{VH})$ and $\mathrm{HV}$ (cross-pole $\mathrm{H}$ received from $\mathrm{V}$ transmitted) signals are available. These returns allow both columns of the backscattering matrix to be measured and calculation of the covariance matrix elements, albeit not all measured at zero time lag (three real power terms and three complex correlations; Doviak and Zrnic 1993). A list of all data fields available from the CSU-CHILL radar is provided in Table 1. An overall summary of the CSU-CHILL radar's current performance characteristics is shown in Table 2.

The enhanced computational speed of the new processor will allow the testing of a faster scanning mode for the acquisition of the polarization parameters. The antenna scan rate is a function of the rate at which independent samples can be acquired and the number of independent samples required for a given accuracy. The polarization parameters such as $Z_{\mathrm{DR}}$ and $\phi_{\mathrm{DP}}$ require high accuracy, which implies a large number of independent samples and traditionally slower scan rates (Sachidananda and Zrnic 1985). By trimming the transmitted pulse width and the receiver gate size, the individual pulse volume (range gate) depth can be reduced to $45 \mathrm{~m}$. Range averaging of groups of five successive 
TABLE 1. Data fields available from the CSU-CHILL system.

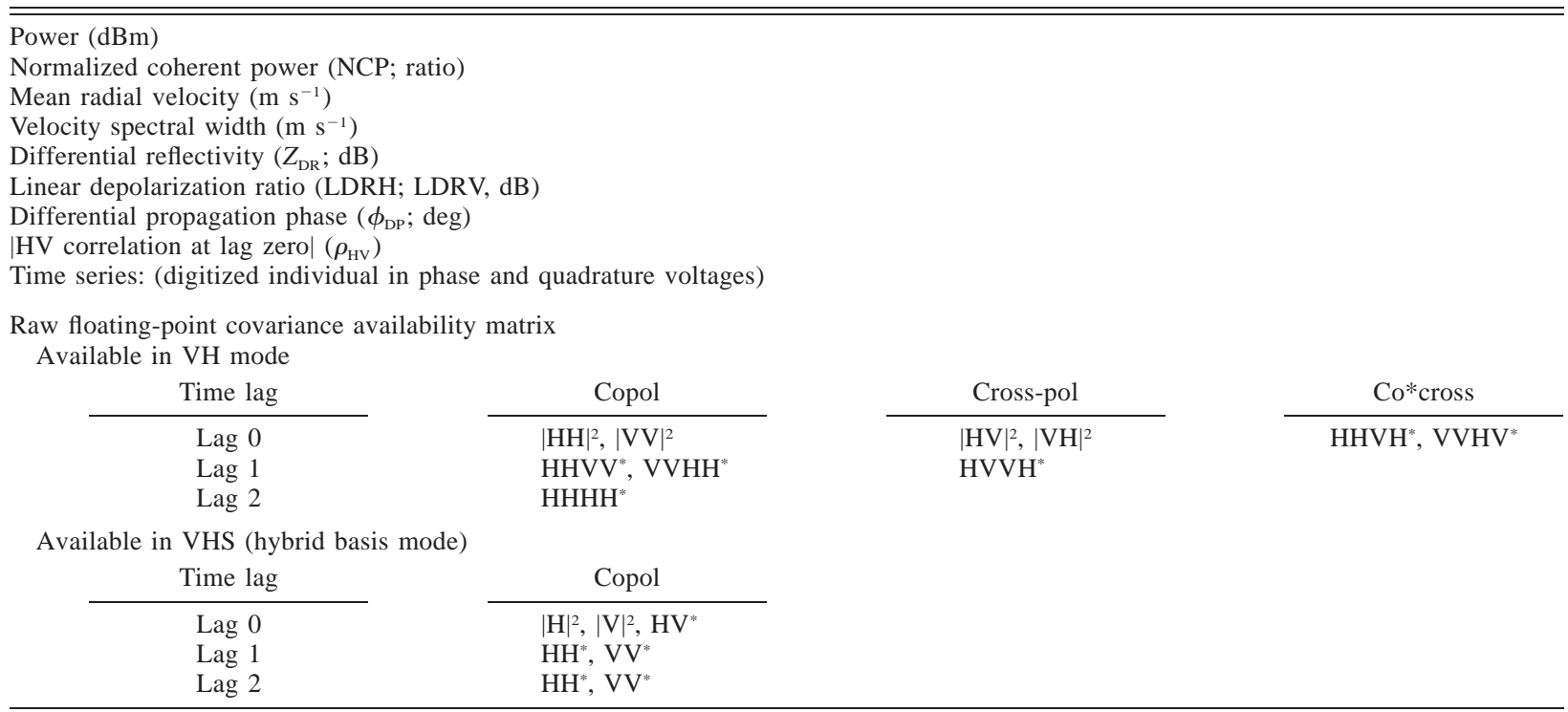

45-m gates yields a final range resolution of $225 \mathrm{~m}$ while increasing the number of independent signal samples by approximately a factor of 4 in comparison to that obtained with a conventional $1-\mu$ s sample (150-m range gate). This rapid acquisition of independent samples allows the antenna scan rate to be doubled during polarimetric data collection while maintaining the same accuracy in the meteorological fields. Azimuth rates of $12^{\circ} \mathrm{s}^{-1}$ are typical of this mode.

\section{c. Data display and recording}

The data stream from the real-time computation system is made available to multiple local workstations via an Ethernet network. Conventional plan views and vertical cross sections can be produced and controlled independently by each workstation. Position tracks can also be overlaid on the radar images to aid in project coordination when working with research aircraft or ground-based chase vehicles. One workstation also has the task of archiving the data on disk files. These files are subsequently moved to $8-\mathrm{mm}$ data cartridges for long-term storage.

\section{Evaluation of antenna performance}

Because of the distributed nature of hydrometeor targets, antenna performance is of prime importance. Accurate dual-polarization measurements require, ideally, matched copolar beam patterns at both polarizations, low copolar and cross-polar sidelobe levels, and high polarization purity throughout the main radiation lobe (Bringi and Hendry 1990). When strong reflectivity gradients exist across the main beam and close-in sidelobes, even slight copolar pattern mismatches can potentially cause significant errors in $Z_{\mathrm{DR}}$ (e.g., Herzegh and Car- bone 1984; Pointin et al. 1988). To reduce such errors it is generally best to reduce the close-in sidelobe levels as much as possible. The cross-polarization pattern for a linearly polarized antenna has maxima that lie in $45 \%$ $135^{\circ}$ planes between the principal axes of the antenna. These maxima consist of a set of four pencil-beam lobes on the $45^{\circ} / 135^{\circ}$ planes (Wood 1980). The new antenna installed on the CSU-CHILL radar in 1994 has maximum cross-polar lobe levels of $-33 \mathrm{~dB}$ in the $45^{\circ} / 135^{\circ}$ planes. The worst-case, close-in copolar sidelobes are less than $-27 \mathrm{~dB}$ in any plane. The measured $135^{\circ}$ plane antenna patterns are shown in Fig. 3.

The (two-way) integrated cross-polar ratio $\left(\mathrm{ICPR}_{2}\right)$ is a figure of merit of dual-polarized antennas and is closely related to the LDR limit of the system (Ussailis and Metcalf 1983). The $\mathrm{ICPR}_{2}$ in the $45^{\circ} / 135^{\circ}$ planes was computed from measured patterns (Fig. 3) and was found to be $-34 \mathrm{~dB}$. The ICPR 2 is defined by

$$
\mathrm{ICPR}_{2}=10 \log _{10}\left[\frac{\int f_{\mathrm{co}} f_{\mathrm{cx}} \sin \theta d \theta}{\int f_{\mathrm{co}}^{2} \sin \theta d \theta}\right],
$$

where $f_{\text {co }}$ and $f_{\text {cx }}$ are the measured copolar and crosspolar patterns, respectively. The CSU-CHILL system routinely measures (lower bound) LDR values in the -33 to $-34 \mathrm{~dB}$ range in spatially homogenous precipitation when the signal-to-noise ratio (SNR) is high (copolar SNR $>\sim 35 \mathrm{~dB}$ ). For example, Fig. 4 shows a scatter plot of $\mathrm{LDR}_{\mathrm{VH}}$ for a number of range profiles measured during the Fort Collins, Colorado, flood event on 28 July 1997 (Petersen et al. 1999). Data points with copolar SNR $>35 \mathrm{~dB}$ are shown. Note that the lowerbound $\mathrm{LDR}_{\mathrm{VH}}$ from the data is very near $-34 \mathrm{~dB} \pm 1$ 
TABLE 2. CSU-CHILL system characteristics.

\begin{tabular}{ll}
\hline \hline Antenna & \\
Shape & Parabolic \\
Diameter & $8.5 \mathrm{~m}$ \\
Feed type & Scalar \\
Gain & $43 \mathrm{~dB}$ (includes waveguide loss) \\
Beamwidth (3dB) & $1.1^{\circ}$ \\
Maximum sidelobe & $-27 \mathrm{~dB}$ (in any $\phi$ plane) \\
Interchannel isolation & $-45 \mathrm{~dB}$ (limited by orothomode transducer) \\
ICPR (two way) & $-34 \mathrm{~dB}$ \\
Transmitters & \\
Wavelength & $11.01 \mathrm{~cm}$ \\
Peak power & $800 \mathrm{~kW}$ \\
Final PA type & VA-87B/C (Klystron) \\
PRT range & $800-2500$ ms \\
Pulse width & $0.3-1.0 \mu \mathrm{s}$ \\
Available polarizations & Horizontal, vertical, slant $45^{\circ} / 135^{\circ}$, right/left circular \\
Receivers/digital signal processing & \\
Noise figure & $\sim 3.4 \mathrm{~dB}$ \\
Noise power (SNR $=1)$ & $\sim-114.0 \mathrm{dBm}$ \\
Dynamic range & $\sim 96 \mathrm{~dB}$ \\
Bandwidth & $750 \mathrm{kHz}$ typ. with programmable filter \\
Output range resolution & $45-\mathrm{m} \mathrm{minimum,} \mathrm{adjustable} \mathrm{upward} \mathrm{in} 15-\mathrm{m}$ intervals \\
Maximum range gates & Estimated to be $>3000$ \\
\hline
\end{tabular}

dB. (The subscript "VH," as in $\mathrm{LDR}_{\mathrm{VH}}$, implies a calculation based on horizontal transmit and vertical receive.)

When the spatial distribution of scatterers is inhomogenous, it is well known that the resultant cross-beam gradients across the main beam and close-in sidelobes can induce antenna pattern related errors, which bias the estimates of $Z_{\mathrm{DR}}, \mathrm{LDR}, \rho_{\mathrm{HV}}$, and, to a lesser extent, $\phi_{\mathrm{DP}}$ (Pointin et al. 1988; Hubbert et al. 1998). In order to estimate the magnitude of the errors in $Z_{\mathrm{DR}}$ and LDR due to gradients across the beam, specified cross-beam profiles of $Z_{\mathrm{HH}}, Z_{\mathrm{DR}}$, and LDR are input to a simulation program. Error estimates are then developed by convolving these input profiles with the antenna patterns measured by the manufacturer in any specified plane

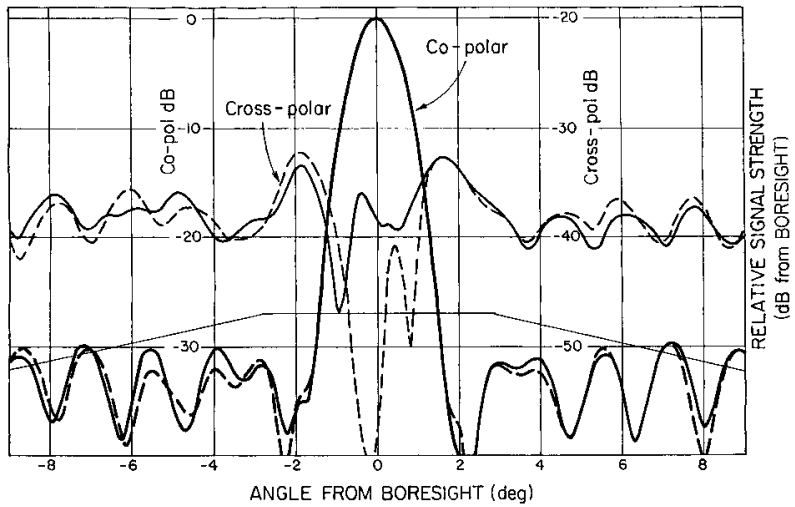

FIG. 3. Copolar and cross-polar power plots. Antenna patterns are in the plane containing the feed horn support structure $\left(\phi=135^{\circ}\right)$ Cross-polar power scale is raised $20 \mathrm{~dB}$ above the copolar power scale. (After Mueller et al. 1995.) $\left(0^{\circ}, 45^{\circ}, 135^{\circ}\right.$, or $\left.90^{\circ}\right)$. For $Z_{\mathrm{DR}}$ the simplest approximation is

$$
Z_{\mathrm{DR}}^{\mathrm{sm}}=10 \log _{10}\left[\frac{\int Z_{\mathrm{HH}} f_{\mathrm{HH}}^{2} d R}{\int Z_{\mathrm{VV}} f_{\mathrm{VV}}^{2} d R}\right],
$$

where $Z_{\mathrm{HH}}$ and $Z_{\mathrm{VV}}$ are the input cross-beam reflectivity profiles and $f_{\mathrm{HH}}$ and $f_{\mathrm{Vv}}$ are the (one way) measured power patterns in the azimuthal $\left(\phi=0^{\circ}\right)$ plane. The

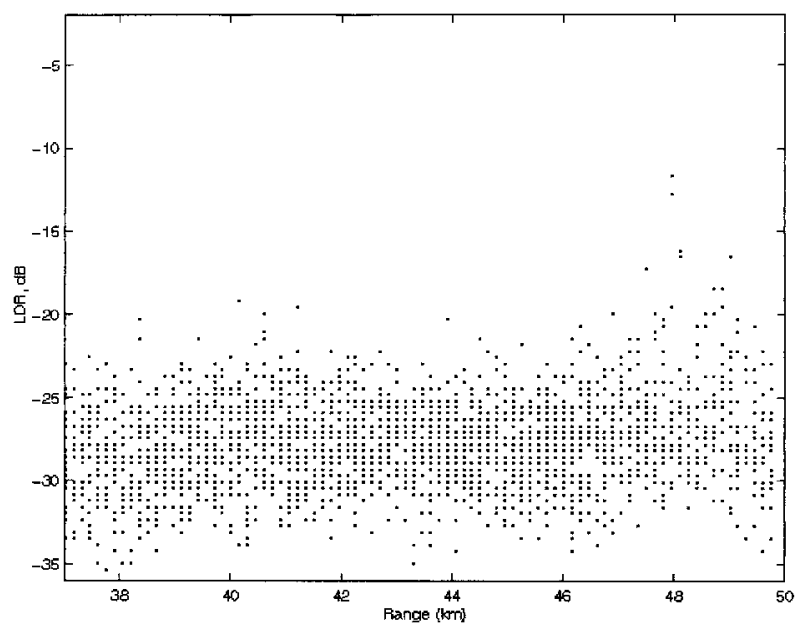

FIG. 4. Scatterplot of LDR (dB) vs range $(\mathrm{km})$ for low elevation angle CSU-CHILL PPI data collected during heavy rain (28-29 Aug 1997). Only LDR values associated with signal-to-noise ratios (SNRs) above $35 \mathrm{~dB}$ are included. 
superscript "sm" on $Z_{\mathrm{DR}}$ (and other variables) refers to the simulated values. Note that all reflectivity units used here are expressed in $\mathrm{mm}^{6} \mathrm{~m}^{-3}$. This equation assumes no cross-polar error due to the antenna and is sufficiently accurate for evaluation of errors in $Z_{\mathrm{DR}}$ due to mis- matches in the main and sidelobes (Herzegh and Carbone 1984).

The approximation for LDR is (Blanchard and Newton 1985)

$$
\mathrm{LDR}^{\mathrm{sm}}=10 \log _{10}\left[\frac{\int\left(Z_{\mathrm{VH}} f_{\mathrm{VV}} f_{\mathrm{HH}}+Z_{\mathrm{HH}} f_{\mathrm{HH}} f_{\mathrm{HV}}+Z_{\mathrm{VV}} f_{\mathrm{VV}} f_{\mathrm{VH}}\right) d R}{\int Z_{\mathrm{HH}} f_{\mathrm{HH}}^{2} d R}\right] \text {, }
$$

where $Z_{\mathrm{HV}}$ is the cross-polar reflectivity profile and $f_{\mathrm{HV}}$ $=f_{\mathrm{VH}}$ is the cross-polar power pattern. An additional term involving $Z_{\mathrm{VH}}\left(f_{\mathrm{VH}}\right)^{2}$ is neglected in the numerator of (3) since it is small in comparison to the other given terms. Because the $\phi=45^{\circ} / 135^{\circ}$ plane (containing the feed support struts and waveguide runs) is the worst for cross-polar errors, the measured antenna patterns for this plane as well as in the $\phi=0^{\circ}$ plane are chosen for the estimation of LDR errors.

The input $Z_{\mathrm{H}}$ profile was chosen to be representative of a hail shaft embedded in rain at a range of $30 \mathrm{~km}$ (Fig. 5a). The reflectivity gradient on the flanks of the hailshaft was chosen to be $30 \mathrm{~dB} \mathrm{~km}^{-1}$. The $Z_{\mathrm{DR}}$ profile sharply increases from 0 to $5 \mathrm{~dB}$ in the rain and then sharply decreases to $\sim 0 \mathrm{~dB}$ in the center of the hail region (Fig. 5b; see also Aydin et al. 1986). The simulated $Z_{\mathrm{DR}}$ profile based on the sampling characteristics of the measured antenna pattern is quite accurate (Fig. $5 b)$ within the constant reflectivity region $(20-25 \mathrm{~km})$. As expected, $Z_{\mathrm{DR}}$ errors can be noted near the maximum gradient region, but these are well known and have been documented (Pointin et al. 1988). Errors are also evident in the simulated LDR profile in the maximum $Z_{\mathrm{H}}$ gradient regions (Fig. 5c). In the high $Z_{\mathrm{H}}$ gradient region, the LDR error is primarily due to the $Z_{\mathrm{HH}} f_{\mathrm{HH}} f_{\mathrm{HV}}$ and the $Z_{\mathrm{VV}} f_{\mathrm{VV}} f_{\mathrm{VH}}$ terms in (3). The LDR errors are slightly worse for cross-beam distances $<19 \mathrm{~km}$ or $>26 \mathrm{~km}$ in the $\phi=45^{\circ}$ plane, where the antenna feed support structure raises the cross-polar sidelobe levels. Within the uniform reflectivity region $(20-25 \mathrm{~km})$, the LDR errors are negligible, since the error is dominated by the $Z_{\mathrm{VH}} f_{\mathrm{VV}} f_{\mathrm{HH}}$ term in (3), and the input LDR exceeds the antenna cross-polar error levels, that is, the result is due to smoothing of the input LDR profile by the copolar pattern. These results show that even with antenna performance approaching the theoretically expected maximum levels for a prime-focus-fed reflector design, radar data may be corrupted in high-reflectivity gradient regions. Experience has shown that the CSU-CHILL LDR and $Z_{\mathrm{DR}}$ values should be viewed with caution in areas where the cross-beam spatial reflectivity gradient exceeds $20-25 \mathrm{~dB} \mathrm{~km}^{-1}$. Antenna performance better than that illustrated here would result only from the use of offset-fed reflector designs, which eliminate beam blockage by the feed support structure.

\section{The $Z_{\mathrm{DR}}$ calibration techniques}

Rainfall estimators based on the combination of $Z$ and $Z_{\mathrm{DR}}$ fields can be significantly affected by small errors in $Z_{\mathrm{DR}}$. Indeed, this is the strongest motivational factor behind the desire to keep the system offset in $Z_{\mathrm{DR}}$ to less than $0.1 \mathrm{~dB}$. The calibration of $Z_{\mathrm{DR}}$ is complicated by the use of two transmitters, which may independently drift a few tenths of a decibel during an operation. Although the average transmitted power is continuously recorded and used to correct the data, additional techniques are required to compensate for subtle systematic offsets in $Z_{\mathrm{DR}}$. One such technique is based on information contained in the LDR fields.

Since the LDR is obtained by taking the ratio of the cross-polar reflectivity to the copolar reflectivity, which are obtained from the output of the two receivers, any residual differential gain between the two receivers must be known to correct the "raw" LDR values. Randomly polarized radiation from the sun will excite both antenna ports equally, and thus daily sun "scans" are used to calibrate the differential gain between the two receivers. As mentioned earlier in section 2b, prior to 1999 the solid state transfer switch had two "states" [e.g., one state, connects the $\mathrm{H}$ port ( $\mathrm{V}$ port) of the antenna to the copolar (cross-polar) receiver and the second state connects the $\mathrm{H}$ port ( $\mathrm{V}$ port) of the antenna to the crosspolar (copolar) receiver]. There are four power outputs, $\mathrm{S}_{1,2,3,4}$, from the sun scans, defined as

$$
\begin{aligned}
& \text { state } 1 \quad\left\{\begin{array}{l}
\mathrm{S} 1 \propto G_{\mathrm{H}} G_{\mathrm{co}} L_{\mathrm{wgh}} \\
\mathrm{S} 2 \propto G_{\mathrm{V}} G_{\mathrm{cr}} L_{\mathrm{wgv}},
\end{array}\right. \\
& \text { state } 2 \quad\left\{\begin{array}{l}
\mathrm{S} 3 \propto G_{\mathrm{V}} G_{\mathrm{co}} L_{\mathrm{wgv}} \\
\mathrm{S} 4 \propto G_{\mathrm{H}} G_{\mathrm{cr}} L_{\mathrm{wgh}},
\end{array}\right.
\end{aligned}
$$

where $G_{\mathrm{H}, \mathrm{V}}$ are the antenna gains referenced to the feedhorn ports, $G_{\mathrm{co}, \mathrm{cr}}$ are the receiver gains referenced to the 

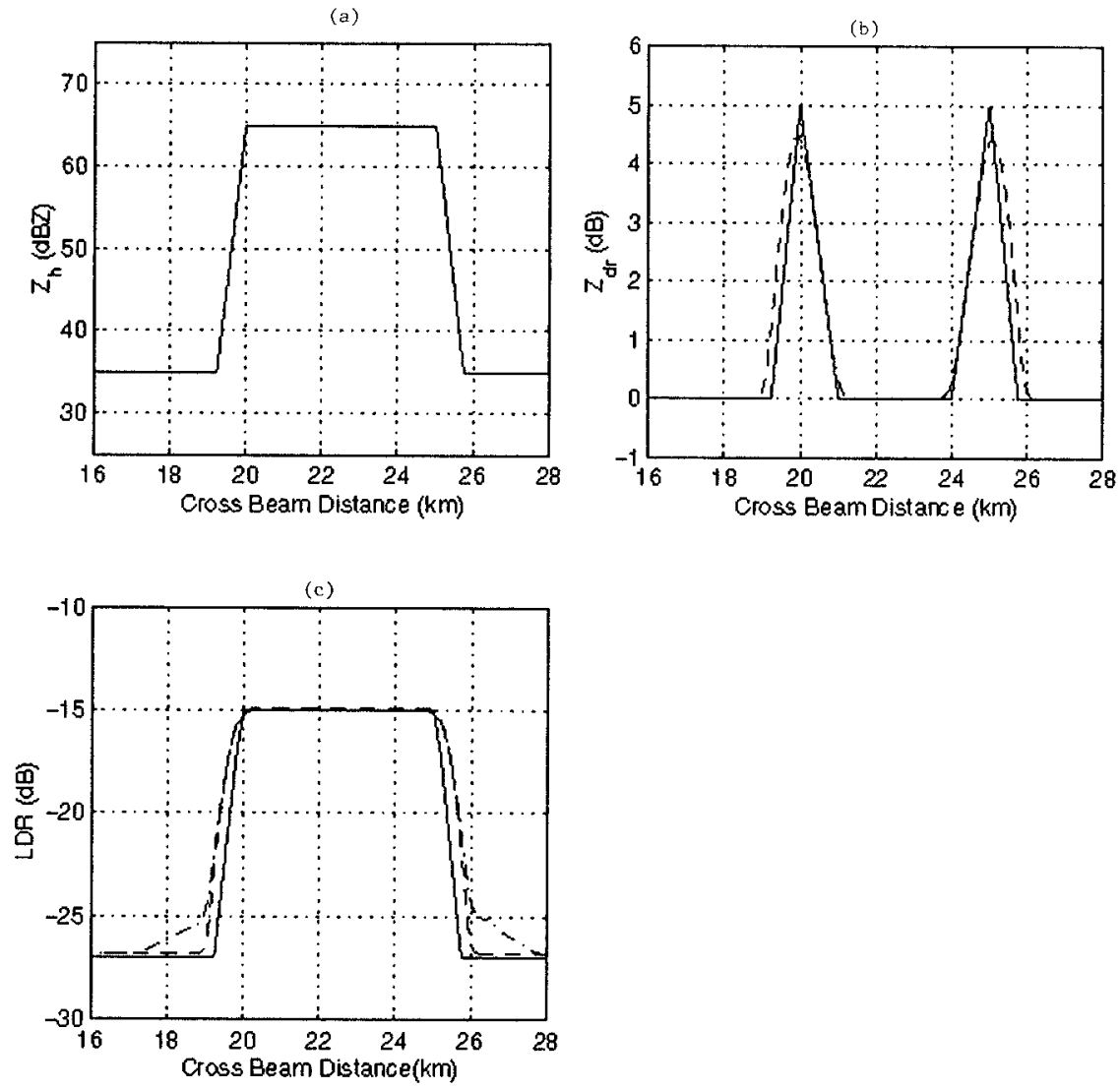

FIG. 5. (a) Input cross-beam $Z_{\mathrm{H}}$ profile that is convolved with the measured CSU-CHILL antenna beam patterns in the radar sampling simulation. (See text for details.) Maximum slope is $30 \mathrm{~dB}$ $\mathrm{km}^{-1}$; simulation is done at a range of $30 \mathrm{~km}$. (b) Input $Z_{\mathrm{DR}}$ profile (solid line) constructed to represent a hail core $\left(Z_{\mathrm{DR}} \sim 0 \mathrm{~dB}\right)$ surrounded by rain (positive $\left.Z_{\mathrm{DR}}\right)$. Simulated radar-observed $Z_{\mathrm{DR}}$ values are shown by the dotted line. (c) Input LDR profile (solid line) corresponding to the hail shaft representation in Fig. 5b. Simulated LDR values are shown by the dotted lines. Note: antenna patterns in the $\phi=0^{\circ}$ and $\phi=45^{\circ}$ (i.e., the plane containing the feed horn support struts) were used in this simulation.

LNA inputs, and $L_{\mathrm{wgh,v}}$ are the waveguide losses for the $\mathrm{H}$ and $\mathrm{V}$ waveguide runs from the feedhorn to the receiver inputs. Two calibration factors relative to the LDR corrections are defined as

$$
\begin{aligned}
& \mathrm{CAL}_{\mathrm{VH}}=10 \log _{10}\left(\frac{\mathrm{S}_{1}}{\mathrm{~S}_{2}}\right) \text { and } \\
& \mathrm{CAL}_{\mathrm{HV}}=10 \log _{10}\left(\frac{\mathrm{S}_{3}}{\mathrm{~S}_{4}}\right) .
\end{aligned}
$$

Note that the radar can measure two linear depolarization ratios $\left(\mathrm{LDR}_{\mathrm{VH}}=\right.$ transmit $\mathrm{H}$, receive $\mathrm{V} ; \mathrm{LDR}_{\mathrm{HV}}=$ transmit $\mathrm{V}$, receive $\mathrm{H}$ ). The corrected LDRs are obtained using

$$
\begin{aligned}
\mathrm{LDR}_{\mathrm{VH}}(\text { corrected })= & \left.\mathrm{LDR}_{\mathrm{VH}} \text { (measured }\right) \\
& +\mathrm{CAL}_{\mathrm{VH}}+L_{r}, \\
\mathrm{LDR}_{\mathrm{HV}}(\text { corrected })= & \mathrm{LDR}_{\mathrm{HV}}(\text { measured }) \\
& +\mathrm{CAL}_{\mathrm{HV}}+L_{r},
\end{aligned}
$$

when $L_{r}$ is the difference in the finite bandwidth loss factors between the cross-polar and copolar receivers (Doviak and Zrnic 1993). As a corollary, an accurate measurement of $Z_{\mathrm{DR}}$ is obtainable, which is independent of the two-channel transmit power difference:

$$
\begin{aligned}
& Z_{\mathrm{DR}}(\text { corrected }) \\
&= 10 \log _{10}\left(Z_{\mathrm{HH}}\right)-10 \log _{10}\left(Z_{\mathrm{VV}}\right) \\
&= 10 \log _{10}\left(\frac{Z_{\mathrm{HV}}}{Z_{\mathrm{VV}}}\right)-10 \log _{10}\left(\frac{Z_{\mathrm{VH}}}{Z_{\mathrm{HH}}}\right) \\
&= \mathrm{LDR}_{\mathrm{HV}}(\text { corrected })-\mathrm{LDR}_{\mathrm{VH}}(\text { corrected }) \\
&= \mathrm{LDR}_{\mathrm{HV}}(\text { measured })-\mathrm{LDR}_{\mathrm{VH}}(\text { measured }) \\
&+\mathrm{CAL}_{\mathrm{HV}}-\mathrm{CAL}_{\mathrm{VH}},
\end{aligned}
$$

where the reciprocity condition $Z_{\mathrm{HV}}=Z_{\mathrm{VH}}$ has been used (Tragl 1990). In practice, the accuracy of $Z_{\mathrm{DR}}$ from (7d) depends on a relatively high SNR in the cross-polar receiver $(\sim 6-8 \mathrm{~dB})$ and on the stability of $\mathrm{CAL}_{\mathrm{HV}}-$ 
$\mathrm{CAL}_{\mathrm{VH}}$. It has been found that $\mathrm{CAL}_{\mathrm{HV}}-\mathrm{CAL}_{\mathrm{VH}}$ is very stable during a continuous radar operation, varying by about $0.09 \mathrm{~dB}$ based on hourly sun scans throughout a day-long test period.

The conventional $Z_{\mathrm{DR}}$ is calculated as the ratio of the average powers at horizontal and vertical polarizations $\left[Z_{\mathrm{DR}}=10 \log _{10}\left(P_{\mathrm{HH}} / P_{\mathrm{VV}}\right)\right]$ obtained from the receiver outputs and is then corrected for any transmit power differences as well as for any unaccounted for system biases (termed $\left.Z_{\mathrm{DRbias}}\right)$. The latter term $\left(Z_{\mathrm{DRbias}}\right)$ is estimated daily from at a value that gives a corrected $Z_{\mathrm{DR}}$ of $0 \mathrm{~dB}$ in the ice anvil region of storms. The hypothesis is that these ice particles (e.g., snow or graupel), because of their low density and random orientation, will on average yield a $Z_{\mathrm{DR}}$ of $0 \mathrm{~dB}$. While this is true at vertical incidence, that is, antenna elevation angle of $90^{\circ}$ and rotated $360^{\circ}$ in azimuth, it is only approximately true at near horizontal incidence (low antenna elevation angles). By comparing conventional $Z_{\mathrm{DR}}$ with the $Z_{\mathrm{DR}}$ derived from $(7 \mathrm{~d})$, it is possible to estimate $Z_{\mathrm{DRbias}}$ using the rain medium as a "calibration" target (as long as differential attenuation can be neglected, an excellent approximation at $\mathrm{S}$ band if the differential phase through the corresponding region is $<50^{\circ}$; Bringi et al. 1990). The conventional method for $Z_{\mathrm{DR}}$ correction is based on

$$
Z_{\mathrm{DR}}^{\text {conv }}(\text { corrected })=Z_{\mathrm{DR}}^{\text {conv }}+\left(P_{\mathrm{V}}^{t}-P_{\mathrm{H}}^{t}\right)+Z_{\mathrm{DRbias}},
$$

and it is equated to $(7 \mathrm{~d})$, yielding a $Z_{\mathrm{DRbias}}$ as

$$
\begin{aligned}
Z_{\mathrm{DRbias}}= & \mathrm{LDR}_{\mathrm{HV}}(\text { measured })-\mathrm{LDR}_{\mathrm{VH}}(\text { measured }) \\
& +\left(\mathrm{CAL}_{\mathrm{HV}}-\mathrm{CAL}_{\mathrm{VH}}\right)-Z_{\mathrm{DR}}^{\text {conv }} \\
& -\left(P_{\mathrm{V}}^{t}-P_{\mathrm{H}}^{t}\right)
\end{aligned}
$$

Note that $P_{\mathrm{H}}^{t}, P_{\mathrm{V}}^{t}$ are the measured (and digitally recorded) average transmitted power values. Once $Z_{\text {DRbias }}$ is obtained using ( $8 \mathrm{~b}$ ) from selected rain data (essentially high SNR and $\phi_{\mathrm{DP}}<50^{\circ}$ ), it can be used in (8a). Selected data can, of course, be from any region of the storm, but from a practical standpoint, the selection of regions with relatively high SNR in the cross-polar receiver is more convenient in the rain region. Figure 6 shows a sample plot of $Z_{\text {DRbias }}$ from ( $8 \mathrm{~b}$ ) versus range in rain. The plot shows the average $Z_{\text {DRbias }}$ as well as the standard deviation and the $95 \%$ confidence interval for the mean. Initial tests with this method of establishing $Z_{\text {DRbias }}$ show that it is stable throughout a given day, the stability being directly related to the stability of $\left(\mathrm{CAL}_{\mathrm{HV}}-\mathrm{CAL}_{\mathrm{VH}}\right)$. This $Z_{\mathrm{DRbias}}$ is being evaluated against conventional vertical incidence measurements in glaciated clouds.

The preceding discussion is applicable to operations prior to 1999 , where the transfer switch was operated to route copolar data to one receiver and cross-polar data to the other receiver. If the transfer switch is not operated, the calibration technique is simplified in that there is a single receiver configuration to consider. The solar measurement yields two powers:

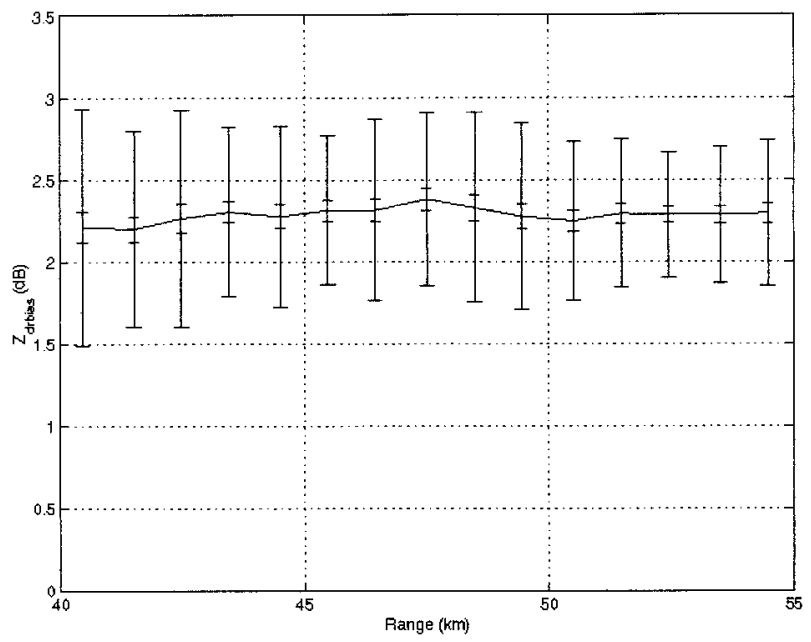

FIG. 6. Shown is $Z_{\mathrm{DRbias}}$ vs range based on 40 rays of CSU-CHILL data collected during the Fort Collins flood of 28-29 Jul 1997. Sample mean value and the $95 \%$ confidence interval for the mean are shown.

$$
\begin{aligned}
& S_{\mathrm{H}} \propto G_{\mathrm{H}} G_{\mathrm{HR}} l_{\mathrm{wgh}}, \\
& S_{\mathrm{V}} \propto G_{\mathrm{V}} G_{\mathrm{VR}} l_{\mathrm{wgv}} .
\end{aligned}
$$

This is similar to (4) except that $G_{\mathrm{HR}}$ and $G_{\mathrm{VR}}$ are the gains of the $\mathrm{H}$ and $\mathrm{V}$ receivers, respectively. The LDR calibration terms in this case are

$$
\begin{aligned}
\mathrm{CAL}_{\mathrm{HV}} & =10 \log _{10}\left(\frac{S_{\mathrm{V}}}{S_{\mathrm{H}}}\right) \text { and } \\
\mathrm{CAL}_{\mathrm{VH}} & =10 \log _{10}\left(\frac{S_{\mathrm{H}}}{S_{\mathrm{V}}}\right) .
\end{aligned}
$$

Observing that $\mathrm{CAL}_{\mathrm{VH}}=-\mathrm{CAL}_{\mathrm{HV}}$, one can substitute $\left(2 \mathrm{CAL}_{\mathrm{HV}}\right)$ or $20 \log _{10}\left(S_{\mathrm{V}} / S_{\mathrm{H}}\right)$ from $(10)$ for $\left(\mathrm{CAL}_{\mathrm{HV}}-\right.$ $\mathrm{CAL}_{\mathrm{VH}}$ ) in Eqs. (7d) and (8b) to get comparable equations for the case where the transfer switch is not operated.

\section{Example data \\ a. VH mode operation}

In addition to the CHILL polarimetric radar, CSU also operates the Pawnee Doppler radar. The Pawnee is an 11-cm wavelength, single polarization, $1.6^{\circ}$ (half-power beamwidth) radar (see Table 3 for specifications). The Pawnee's real-time capabilities for radar control as well as data display and recording are comparable to those of the CSU-CHILL system, facilitating the conduct of coordinated scanning. The Pawnee is located $48 \mathrm{~km}$ north-northwest of the CSU-CHILL site, permitting dual-Doppler data collection over an area including portions of the eastern slopes of the Rocky Mountains and the adjacent high plains (Fig. 7).

An example analysis utilizing the CSU-CHILL and Pawnee radars is shown in Fig. 8. The radar data were 
30 DEGREE LOBES

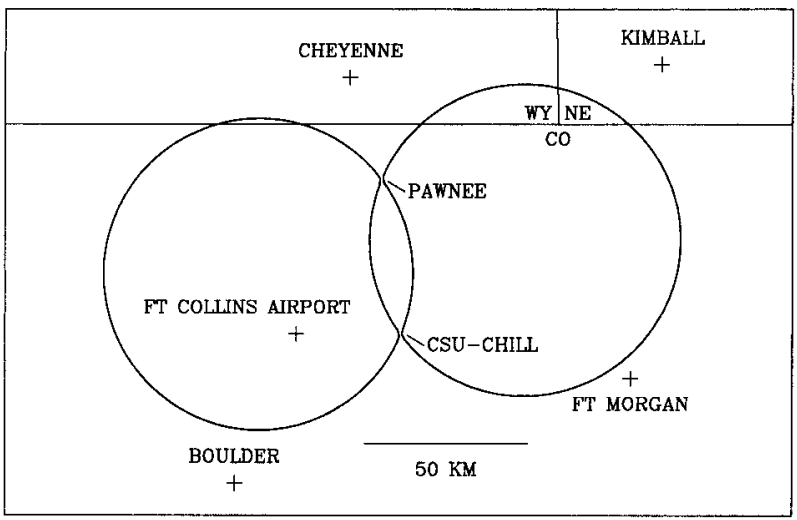

FIG. 7. The CSU-CHILL and Pawnee radar dual-Doppler network. Lobes define the regions where the difference between the azimuths of the viewing radials from the two radars exceeds $30^{\circ}$.

collected in synchronized plan position indicator (PPI) sector volume scans over the eastern dual-Doppler lobe. These scans were centered on an area of intense convection that was developing an extensive region of trailing stratiform precipitation (Rutledge et al. 1988). The convective region is centered near $X=59 \mathrm{~km}$, where the reflectivity contours are most vertically oriented and the dual-Doppler wind retrieval contains the strongest updrafts aloft. Within this echo core, $Z_{\mathrm{DR}}$ values of less than $0.5 \mathrm{~dB}$ reach down to the lowest analysis height (1.5 km MSL; terrain elevation is approximately $1.3 \mathrm{~km}$ MSL). The combination of $\mathrm{dBZ}>55 \mathrm{dBZ}, Z_{\mathrm{DR}}<0.5$ $\mathrm{dB}$, and LDR values of -24 to $-20 \mathrm{~dB}$ is indicative of hail (Herzegh and Jameson 1992). In advance of the surface hail signature $(X=66 \mathrm{~km}), Z_{\mathrm{DR}}$ values exceeding $1.5 \mathrm{~dB}$ extend to heights of $6.5 \mathrm{~km}$, well above the
TABLE 3. CSU-Pawnee radar characteristics.

\begin{tabular}{ll}
\hline \hline Wavelength & $10.99 \mathrm{~cm}$ \\
Beamwidth $(3 \mathrm{~dB})$ & $1.6^{\circ}$ \\
Peak transmit power & $380 \mathrm{~kW}$ \\
Pulse duration & $1 \mu \mathrm{s}$ \\
Pulse repetition frequency & $500-1200 \mathrm{~Hz}$ \\
Noise power (SNR $=1)$ & $-109 \mathrm{dBm}$ \\
Polarization & $\mathrm{V}$ \\
Pulses per integration cycle & $40-2048$ \\
Latitude & $40.871^{\circ} \mathrm{N}$ \\
Longitude & $104.715^{\circ} \mathrm{W}$ \\
Horn elevation & $1688 \mathrm{~m} \mathrm{MSL}$ \\
\hline
\end{tabular}

ambient $0^{\circ} \mathrm{C}$ height $(\sim 4.5 \mathrm{~km})$. The occurrence of such distinctly positive $Z_{\mathrm{DR}}$ values at subfreezing temperatures suggests that large, oblate supercooled drops have been lofted above the freezing level (Illingworth et al. 1987). A separate surfaced-based positive $Z_{\mathrm{DR}}$ area is found in the higher reflectivity portions of the stratiform region $(X=36$ to $X=55 \mathrm{~km})$, where appreciable concentrations of oblate raindrops are present (Seliga and Bringi 1976).

A descending rear inflow jet originating near $Z=6.5$ $\mathrm{km}, X=22 \mathrm{~km}$ is evident near the western edge of Fig. 8 . Immediately below this jet, the $30-\mathrm{dBZ}$ reflectivity contour outlines a brightband echo pattern centered near $Z=4 \mathrm{~km} \mathrm{MSL}$. The melting particles passing through this band produce locally positive $Z_{\mathrm{DR}}$ 's and increase the LDR levels to $\sim-20 \mathrm{~dB}$.

Figure 9 shows an extraction of CSU-CHILL data from a vertical column that intercepts this bright band echo. As reported in Zrnic et al. (1993), the maximum positive $Z_{\mathrm{DR}}$ value occurs at a height slightly below the altitude of the greatest reflectivity. Depolarization levels are maximized within the melting zone, where wet, non-

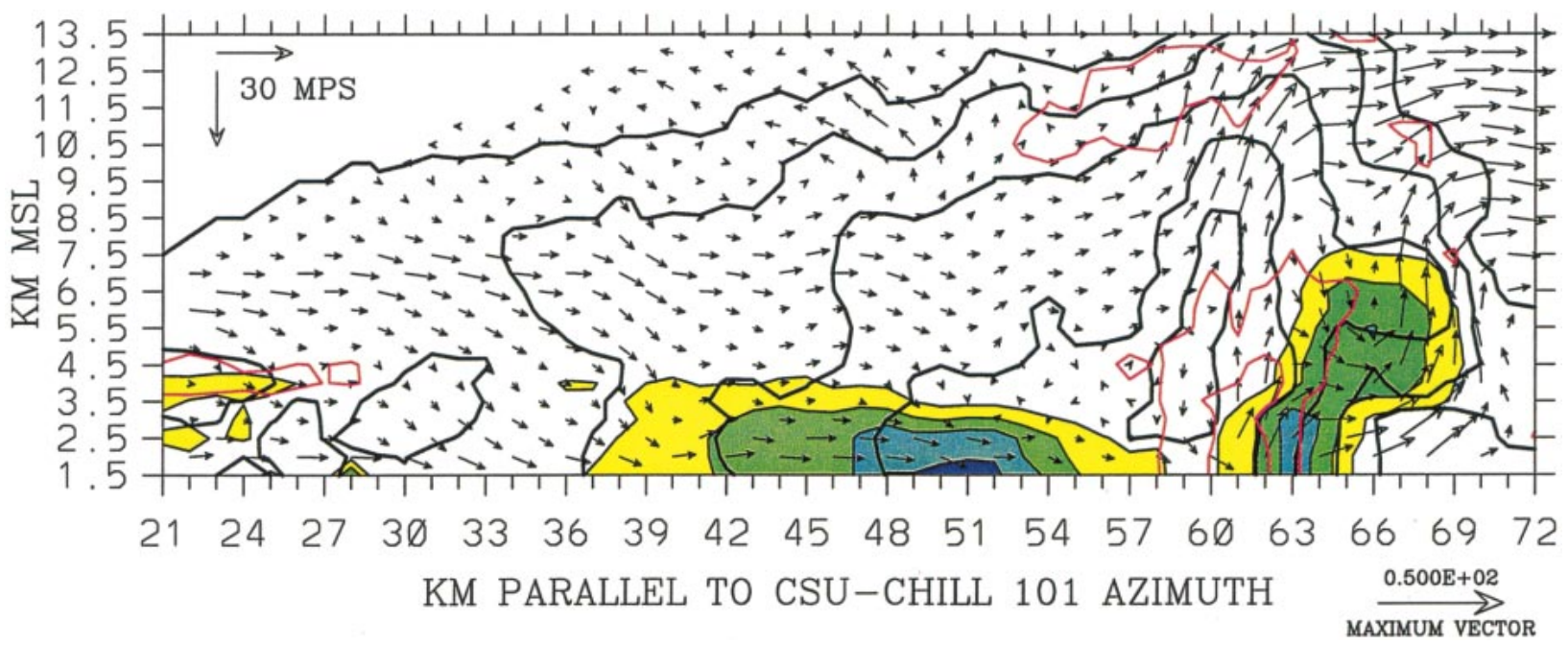

FIG. 8. Vertical cross section developed from synchronized CSU-CHILL and Pawnee radar volume scans starting at 0215 UTC 3 Sep 1999. The analysis plane is oriented approximately along the direction of storm motion. Black contours are CSU-CHILL reflectivity (minimum contour is $20 \mathrm{dBZ}$; increment is $10 \mathrm{~dB})$. Dual-Doppler-based wind vectors are earth relative $\left(\mathrm{m} \mathrm{s}^{-1}\right)$. Solid color-filled contours are $Z_{\mathrm{DR}}$ (minimum contour is $0.5 \mathrm{~dB}$; increment is $1 \mathrm{~dB}$ ). Solid red contours are the -24 - and -18-dB LDR levels. 


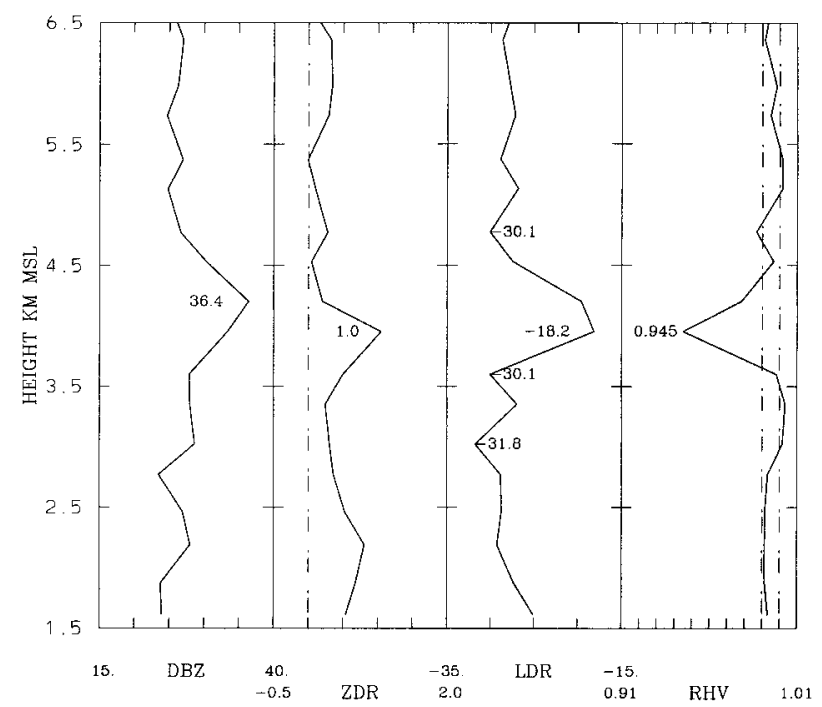

FIG. 9. CSU-CHILL data vertical profiles through a bright band as extracted from the volume scan starting at 0215 UTC 3 Sep 1999. The plotted data are range averages over the three consecutive gates in each PPI sweep that are centered nearest to an azimuth of $101^{\circ}$ and a range of $20 \mathrm{~km}$. The profiles are annotated with selected data values. Reference values are shown with dashed vertical lines: $0 \mathrm{~dB}$ in the $Z_{\mathrm{DR}}$ panel; 0.99 and 1.00 correlations in the $\rho_{\mathrm{HV}}$ panel.

spherical ice particles with fluctuating orientations are most likely to be present (Illingworth and Caylor 1989). LDR levels are distinctly low (often less than $\sim-30$ $\mathrm{dB})$ at heights outside of the melting zone. Similarly, $\rho_{\mathrm{HV}}$ values are quite high $(0.99$ to 1.0$)$, except within the melting zone, where both irregularly shaped ice particles and melted drops coexist (Balakrishnan and Zrnic 1990; Zrnic et al. 1993).

\section{b. Hybrid basis mode}

We mentioned in section $2 \mathrm{a}$ that the transmitters may be triggered either alternately or simultaneously. With the alternate $\mathrm{VH}$ mode, the conventional estimates of $Z_{\mathrm{DR}}, \phi_{\mathrm{DP}}$, and $\rho_{\mathrm{HV}}$ are formed from the copolar $\mathrm{HH}$ and VV signals available at the input to the digital receivers on the even and odd pulse intervals, respectively. At the same time, the cross-polar $\mathrm{VH}$ and $\mathrm{VH}$ signals are available at the input to the opposite receiver. This scheme is based on the classical orthogonal basis.

When the transmitters are triggered simultaneously with matched power outputs, the radiated polarization state can be described by the unit vector

$$
\mathbf{e}=\frac{\mathbf{h}+e^{j \theta} \mathbf{v}}{\sqrt{2}},
$$

where $\theta$ is the phase difference between the two transmit channels. While $\theta$ can be controlled via an I/Q vector modulator, for the purposes of this discussion, $\theta$ will be treated as an unknown but fixed system constant. The two receivers are used to measure the elements of the coherency matrix, defined as

$$
\overline{\bar{J}}=\left[\begin{array}{cc}
\left\langle E_{\mathrm{H}}^{\mathrm{r}} E_{\mathrm{H}}^{\mathrm{r} *}\right\rangle & \left\langle E_{\mathrm{H}}^{\mathrm{r}} E_{\mathrm{V}}^{\mathrm{r} *}\right\rangle \\
\left\langle E_{\mathrm{V}}^{\mathrm{r}} E_{\mathrm{H}}^{\mathrm{r} *}\right\rangle & \left\langle E_{\mathrm{V}}^{\mathrm{r}} E_{\mathrm{V}}^{\mathrm{r} *}\right\rangle
\end{array}\right],
$$

where $E_{\mathrm{H}}^{\mathrm{r}}$ and $E_{\mathrm{V}}^{\mathrm{r}}$ are the horizontal and vertical polarized components of the backscattered ellipse, a double bar indicating a matrix. Since the solid state transfer switch is not activated in this mode, the horizontally polarized component is received by the first receiver and the vertically polarized component is received by the second receiver. The $Z_{\mathrm{DR}}, \psi_{\mathrm{DP}}$, and $\rho_{\mathrm{HV}}$ in this hybrid mode are obtained as

$$
\begin{aligned}
& Z_{\mathrm{DR}}^{\mathrm{hy}}=10 \log _{10}\left[\frac{\left\langle\left|E_{\mathrm{H}}^{\mathrm{r}}\right|^{2}\right\rangle}{\left\langle\left|E_{\mathrm{V}}^{\mathrm{r}}\right|^{2}\right\rangle}\right], \\
& \Psi_{\mathrm{DP}}^{\mathrm{hy}}=\arg \left(\left\langle E_{\mathrm{H}}^{\mathrm{r} *} E_{\mathrm{V}}^{\mathrm{r}}\right\rangle\right), \\
& \rho_{\mathrm{HV}}^{\text {hy }}=\frac{\left|\left\langle E_{\mathrm{H}}^{\mathrm{r} *} E_{\mathrm{V}}^{\mathrm{r}}\right\rangle\right|}{\sqrt{\left\langle\left|E_{\mathrm{H}}^{\mathrm{r}}\right|^{2}\right\rangle\left\langle\left|E_{\mathrm{V}}^{\mathrm{r}}\right|^{2}\right\rangle}} .
\end{aligned}
$$

Angle brackets denote time averages. This measurement scheme is termed the hybrid basis as opposed to the classical orthogonal basis described in the beginning of this section. It is interesting to note that both schemes were suggested by Seliga and Bringi (1976) as possible for $Z_{\mathrm{DR}}$ measurements.

Measurements in the hybrid basis will, in principle, lead to no error if the propagation and scattering matrices are diagonal, since the received electric field components can be expressed as

$$
\begin{aligned}
{\left[\begin{array}{c}
E_{\mathrm{H}}^{\mathrm{r}} \\
E_{\mathrm{V}}^{\mathrm{r}}
\end{array}\right]=} & \sqrt{\frac{Z_{0} G P_{t}}{2 \pi}} \frac{1}{r^{2}}\left[\begin{array}{cc}
e^{\lambda_{1} r} & 0 \\
0 & e^{\lambda_{2} r}
\end{array}\right]\left[\begin{array}{cc}
S_{\mathrm{HH}} & 0 \\
0 & S_{\mathrm{VV}}
\end{array}\right]\left[\begin{array}{cc}
e^{\lambda_{1} r} & 0 \\
0 & e^{\lambda_{2} r}
\end{array}\right] \\
& \times\left[\begin{array}{c}
\frac{1}{\sqrt{2}} \\
\frac{1}{\sqrt{2}} e^{j \theta}
\end{array}\right]
\end{aligned}
$$

where $\lambda_{1}$ and $\lambda_{2}$ are the eigenvalues of the propagation medium (Oguchi 1983); $S_{\mathrm{HH}}$ and $S_{\mathrm{Vv}}$ are elements of the scattering matrix of the resolution volume centered at range $r$; and $Z_{0}, G$, and $P_{t}$ are the intrinsic impedance of vacuum, antenna gain, and peak transmitted power, respectively. If the propagation medium is nonattenuating and imposes a pure differential phase (a good approximation for propagation in rain at $S$ band), then it is easily verified that (e.g., Sachidananda and Zrnic 1985)

$$
\begin{aligned}
Z_{\mathrm{DR}}^{\mathrm{hy}} & =10 \log _{10}\left[\frac{\left\langle\left|S_{\mathrm{HH}}\right|^{2}\right\rangle}{\left\langle\left|S_{\mathrm{VV}}\right|^{2}\right\rangle}\right], \\
\Psi_{\mathrm{DP}}^{\mathrm{hy}} & =\arg \left(\left\langle S_{\mathrm{HH}}^{*} S_{\mathrm{VV}}\right\rangle\right)+\Phi_{\mathrm{DP}}+\theta=\Phi_{\mathrm{DP}}+\theta, \\
\rho_{\mathrm{co}}^{\mathrm{hy}} & =\frac{\left|\left\langle S_{\mathrm{HH}}^{*} S_{\mathrm{VV}}\right\rangle\right|}{\sqrt{\left\langle\left|S_{\mathrm{HH}}\right|^{2}\right\rangle\left\langle\left|S_{\mathrm{VV}}\right|^{2}\right\rangle}},
\end{aligned}
$$



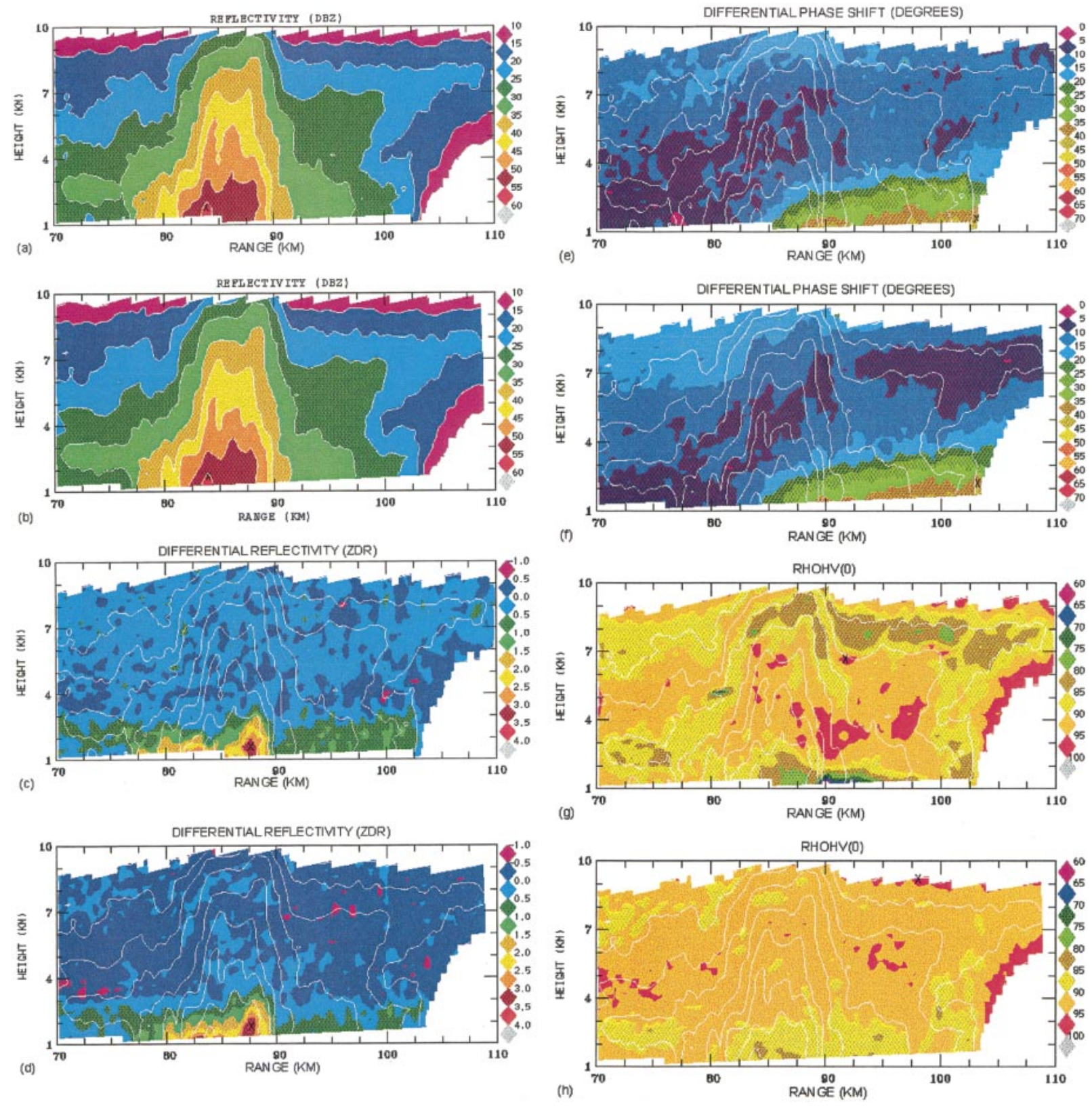

FIG. 10. Comparative vertical cross sections from 11 Aug 1998 taken in conventional VH mode (a, c, e, g) and hybrid basis mode (b, d, f, h). Fields shown are reflectivity, $Z_{\mathrm{DR}}, \Phi_{\mathrm{DP}}$, and $\rho_{\mathrm{HV}}$, respectively.

where $\Phi_{\mathrm{DP}}=2\left[k_{\mathrm{eff}}^{\mathrm{H}}-k_{\mathrm{eff}}^{\mathrm{V}}\right] r$ with $\lambda_{1}=-j k_{\mathrm{eff}}^{\mathrm{H}}$ and $\lambda_{2}=$ $-j k_{\mathrm{eff}}^{\mathrm{V}}\left(k_{\mathrm{eff}}^{\mathrm{H}, \mathrm{V}}\right.$ are the effective wave numbers of the propagation medium). Equation (15) shows that no error is incurred in the hybrid $Z_{\mathrm{DR}}$ and hybrid $\rho_{\mathrm{co}}$, while the hybrid $\Phi_{\mathrm{DP}}$ is just shifted by $\theta$. Note that Rayleigh scattering by raindrops at $\mathrm{S}$ band is assumed.

Fields of $Z_{\mathrm{HH}}, Z_{\mathrm{DR}}, \Phi_{\mathrm{DP}}$, and $\rho_{\mathrm{co}}$ calculated in the conventional and hybrid modes are compared in Fig. 10. The time difference between the data collected in the two modes is approximately $30 \mathrm{~s}$. Figure 10 shows an RHI scan through the core of a convective storm located at a range of approximately $90 \mathrm{~km}$. The reflec- tivity $\left(Z_{\mathrm{HH}}\right)$ in the two modes is in excellent agreement, as seen in the Figs. 10a and 10b. The $Z_{\mathrm{DR}}$ is compared in Figs. 10c and 10d and is also seen to be in very good agreement. Note that any systematic offsets in the hybrid-mode $Z_{\mathrm{DR}}$ may be calibrated out in postprocessing. The $\Phi_{\mathrm{DP}}$ data are compared in Figs. 10e and 10f and are also seen to be in excellent agreement. An overall system $\Phi_{\mathrm{DP}}$ bias of $50^{\circ}$ was added to the conventionalmode $\Phi_{\mathrm{DP}}$ data to facilitate the intercomparison. The $Z_{\mathrm{HH}}, Z_{\mathrm{DR}}, \Phi_{\mathrm{DP}}$, and $\rho_{\mathrm{co}}$ data in both modes were processed and plotted in exactly the same way. The largest discrepancy was noted in the $\rho_{\text {co }}$ data (expressed as a 
percentage) from the two modes, as shown in Figs. $10 \mathrm{~g}-\mathrm{h}$. The conventional mode $\rho_{\text {co }}$ is seen to be lower, particularly within the highest reflectivity region near $1-\mathrm{km}$ height and also near the storm top. It is known from simulations that the conventional-mode $\rho_{\text {co }}$ will be biased low (by 5\%-15\%) when the Doppler spectral shape is not Gaussian (either very broad shape or spectra with multiple peaks; Liu et al. 1994), which can likely occur in severe storms. On the other hand, the hybridmode $\rho_{\text {co }}$ can be biased low due to the so-called backscatter depolarization effect modeled by Doviak et al. (2000). This tendency does not stand out when comparing Figs. $10 \mathrm{~g}$ and $10 \mathrm{~h}$, though it may be noted near a range of $90 \mathrm{~km}$ and a height of $3 \mathrm{~km}$, where conventional $\rho_{\text {co }}$ is around 95\%-100\% whereas the hybridmode $\rho_{\text {co }}$ is $85 \%-95 \%$. These initial data comparisons suggest that the hybrid scheme should be further explored for application to operational radar systems (Doviak et al. 2000).

\section{Overview of the CSU-CHILL facility}

\section{a. Radar packaging and transportability}

The CSU-CHILL system is designed to be moved to support data collection at locations other than the home base near Greeley, Colorado. The entire radar system is transportable on five 14.6-m-long (48 ft) semitrailers. Only three of these trailers (the transmitter, user, and equipment storage vans) need to be at the radar site during operations. The forward portion of the user van provides an $8.5 \mathrm{~m}$ by $2.1 \mathrm{~m}(28 \mathrm{ft}$ by $7 \mathrm{ft})$ controlled environment space from which real-time radar operations are directed (Mueller et al. 1995). This user area also has ample space to accommodate special projectrelated equipment (radios, additional workstations, etc.).

The CSU-CHILL antenna is protected by an air-inflated radome constructed of reinforced nylon material. This radome has an equatorial diameter of $22.3 \mathrm{~m}$ and a maximum height of $16.2 \mathrm{~m}$. Support for the combined antenna pedestal and radome system is provided by a 19.8-m-diameter reinforced concrete foundation. This foundation was recently redesigned to decrease the amount of concrete needed, thereby significantly reducing the cost of the pad installation. Additional details concerning the remote deployment of the system may be obtained at the facility Web site.

\section{b. Real-time radar operation and data dissemination}

Real-time operation of the CSU-CHILL system is done via fully interactive control software. The specific data collection parameters (antenna scan angular limits, transmitter pulse repetition frequency, etc.) are collected into an arbitrary number of predefined scan segments, which are loaded from computer files as needed. The segment parameters may also be easily modified during operations. PPI scan optimization is optionally per- formed while the scan is in progress. If enabled, the scan optimizer chooses each elevation scan angle based on minimum spatial resolution requirements established by the operator. Each scan segment describes the signal processor and radar operating parameters as well as the basic antenna motion (i.e., which axis is scanning, scan rate, scan limits, etc.). These scan segments may be activated in an arbitrary order by the operator or linked together to define a repeating sequence of scans. Timers can be established to start specific scan segments at specific times and/or recurrence intervals. This radar control arrangement readily permits the data acquisition scheme to be synchronized with other radars and to be adapted as the echoes of interest evolve and move.

Color displays of the radar data fields are available in real time on a ray-by-ray basis in the user van. Selected color display images (typically four data fields from one sweep in a particular scan segment) can be transferred onto the CSU-CHILL Web site. These saved images are available for viewing within seconds of the completion of the sweep to be saved. Also, Internet communication techniques are under development that will permit investigators who are not physically at the user van to access the radar's real-time data acquisition parameters and to input scan modifications. Thus, it is anticipated that in the near future, researchers will be able to remotely direct real-time CSU-CHILL operations.

All CSU-CHILL data are routinely recorded on 8-mm magnetic tape cartridges. These field tapes may easily be replayed through the radar's color display system. Copies of the archived data may also be rapidly converted to various "standard" formats, including Universal Doppler Exchange Format (Barnes 1980).

\section{Summary}

As presently configured, the CSU-CHILL is a transportable S-band radar system providing an instrument for the collection of research-quality multiparameter radar data. With the dual-transmitter and dual-receiver configuration, maximum polarimetric performance is obtained from a prime-focus reflector antenna. The recent upgrade of the radar's data processing system will permit the antenna scan rate to be nearly doubled while multiparameter data are being collected.

An immediate application of this performance improvement will be the collection of higher time resolution dual-Doppler and polarimetric datasets using the CSU-CHILL and Pawnee radar network. It is expected that the resultant high time resolution, combined dualDoppler, and multiparameter radar datasets will provide new insights into storm dynamics, precipitation processes, and cloud electrification mechanisms.

Prospective radar users should consult the facility's Web site (http://chill.colostate.edu) for access to archived data as well as current facility information. 
Acknowledgments. Mr. Gwo-Jong Huang performed the antenna pattern convolution modeling runs. The CSU-CHILL National Radar Facility is sponsored by the National Science Foundation under Grant ATM9500108 and by Colorado State University. SAR, VNB, and VC also acknowledge support from the U.S. Weather Research Program via the NSF under Grant ATM9612519. Expert technical support of the facility was also provided by Kenneth Pattison.

\section{REFERENCES}

Aydin, K., T. A. Seliga, and B. Balaji, 1986: Remote sensing of hail with a dual linear polarization radar. J. Climate Appl. Meteor., 25, 1475-1481.

Balakrishnan, N., and D. S. Zrnic, 1990: Use of polarization to characterize precipitation and discriminate large hail. J. Atmos. Sci., 47, $1525-1540$

Barnes, S. L., 1980: Report on a meeting to establish a common Doppler radar data exchange format. Bull. Amer. Meteor. Soc., 61, 1401-1404.

Blanchard, J., and R. W. Newton, 1985: Demands on polarization purity in the measurement and imaging of distributed clutter. Mathematical and Physical Sciences, W. Boerner, Ed., NATO ASI Series C, Vol. 153, D. Reidel, 721-738.

Bringi, V. N., and A. Hendry, 1990: Technology of polarization diversity radars for meteorology. Radar in Meteorology, D. Atlas, Ed., Amer. Meteor. Soc., 153-190.

—, V. Chandrasekar, N. Balakrishnan, and D. S. Zrnic, 1990: An examination of propogation effects in rainfall on radar measurements at microwave frequencies. J. Atmos. Oceanic Technol., 7, 829-840

Carter, J. K., D. Sirmans, and J. Schmidt, 1986: Engineering description of the NSSL dual linear polarization Doppler weather radar. Preprints, 23d Radar Meteorology Conf., Snowmass, CO, Amer. Meteor. Soc., 381-384.

Doviak, R. I., and D. S. Zrnic, 1993: Doppler Radar and Weather Observations. Academic Press, $562 \mathrm{pp}$

—, V. Bringi, A. Ryzhkov, A. Zahari, and D. S. Zrnic, 2000: Considerations for polarimetric upgrades to operational WSR-88D radars. J. Atmos. Oceanic Technol., 17, 257-278.

Herzegh, P. H., and R. E. Carbone, 1984: The influence of antenna illumination function characteristics on differential reflectivity measurements. Preprints, 22d Radar Meteorology Conf., Zurich, Switzerland, Amer. Meteor. Soc., 281-286.

_ , and A. R. Jameson, 1992: Observing precipitation formation through dual-polarization radar measurements. Bull. Amer. Meteor. Soc., 73, 1365-1374.

Hubbert, J., V. N. Bringi, L. D. Carey, and S. Bolen, 1998: CSUCHILL polarimetric radar measurements from a severe hailstorm in eastern Colorado. J. Appl. Meteor., 37, 749-775.

Illingworth, A. J., and I. J. Caylor, 1989: Cross polar observations of the bright band. Preprints, 24th Conf. on Radar Meteorology, Tallahassee, FL, Amer. Meteor. Soc., 323-327.

— J. W. F. Goddard, and S. M. Cherry, 1987: Polarization radar studies of precipitation development in convective storms. Quart. J. Roy. Meteor. Soc., 113, 469-489.
Jameson, A. R., 1985: On deducing the microphysical character of precipitation from multiple-parameter radar polarization measurements. J. Climate Appl. Meteor., 24, 1037-1047.

, and D. B. Johnson, 1990: Cloud microphysics and radar. Radar in Meteorology, D. Atlas, Ed., Amer. Meteor. Soc., 323347.

Liu, L., V. N. Bringi, V. Chandrasekar, E. A. Mueller, and A. Mudukutore, 1994: Analysis of the co-polar correlation coefficient between horizontal and vertical polarizations. J. Atmos. Oceanic Technol., 11, 950-963.

McCormick, G. C., 1981: Polarization errors in a two channel system. Radio Sci., 16, 67-75.

— , and A. Hendry, 1975: Principles for the radar determination of the polarization properties of precipitation. Radio Sci., 10, 421434.

_, and 1979: Techniques for the determination of the polarization properties of precipitation. Radio Sci., 14, 1027-1040.

Mueller, E. A., 1981: Implementation of differential reflectivity on the CHILL radar. Preprints, 20th Radar Meteorology Conf., Boston, MA, Amer. Meteor. Soc., 666-667.

— , and E. J. Silha, 1978: Unique features of the CHILL radar system. Preprints, 18th Radar Meteorology Conf., Atlanta, GA, Amer. Meteor. Soc., 381-382.

—, S. A. Rutledge, V. N. Bringi, D. Brunkow, P. C. Kennedy, K. Pattison, R. Bowie, and V. Chandrasekar, 1995: CSU-CHILL radar upgrades. Preprints, 27th Radar Meteorology Conf., Vail, CO, Amer. Meteor. Soc., 703-706.

Oguchi, T., 1983: Electromagnetic wave propagation and scattering in rain and other hydrometeors. Proc. IEEE, 71, 1029-1078.

Petersen, W. A., and Coauthors, 1999: Mesoscale and radar observations of the Fort Collins flash flood of 28 July 1997. Bull. Amer. Meteor. Soc., 80, 191-216.

Pointin, Y., D. Ramond, and J. Fournet-Fayard, 1988: Radar differential reflectivity $Z_{\mathrm{DR}}$ : A real-case evaluation of errors induced by antenna characteristics. J. Atmos. Oceanic Technol., 5, 416423.

Rutledge, S. A., R. A. Houze Jr., M. I. Biggerstaff, and T. Matejka, 1988: The Oklahoma-Kansas mesoscale convective system of 10-11 June 1985: Precipitation structure and single-Doppler radar analysis. Mon. Wea. Rev., 116, 1409-1430.

Sachidananda, M., and D. S. Zrnic 1985: $Z_{\mathrm{DR}}$ measurement consideration for a fast scan capability radar. Radio Sci., 20, 907-922.

Seliga, T. A., and V. N. Bringi, 1976: Potential use of radar differential reflectivity measurements at orthogonal polarizations for measuring precipitation. J. Appl. Meteor., 15, 69-76.

Tragl, K., 1990: Polarimetric radar backscattering from reciprocal random targets. IEEE Trans. Geosci. Remote Sens., 8, 856-864.

Ussailis, J. S., and J. I. Metcalf, 1983: Analysis of a polarization diversity meteorological radar design. Preprints, 21st Radar Meteorology Conf., Edmonton, AB, Canada, Amer. Meteor. Soc., 331-338.

Wood, P. J., 1980: Reflector Antenna Analysis and Design. Peregrinus, $226 \mathrm{pp}$.

Wu, Y., 1998: Design of digital radar receivers. IEEE Aerospace and Electronic Systems Magazine Vol. 8, No. 1, 35-41.

Zrnic, D. S., N. Balakrishnan, C. L. Ziegler, V. N. Bringi, K. Aydin, and T. Matejka, 1993: Polarimeteric signatures in the stratiform region of a mesoscale convective system. J. Appl. Meteor., 32, 678-693. 